\title{
Examining Similarities and Differences among Pharmacy Educational Mobile Applications
}

\author{
Serge A. Afeli, PhD, CGBP
}

Presbyterian College School of Pharmacy, Clinton, South Carolina

\begin{abstract}
The use of educational mobile applications (EMAs) to enhance student learning experience is gaining considerable interest across college campuses in the United States (U.S). Some EMAs are more commendable than others because of their ability to effectively help students study lecture materials, learn new concepts, prepare for exams, and improve their overall academic performance. The aim of this commentary is to highlight the major EMAs currently available to pharmacy students, while addressing the similarities and differences between them.
\end{abstract}

Key words: educational mobile applications, pharmacy education, active learning, drugs brand names

\section{Introduction}

In 2016, the U.S. corporate and academic e-learning sector was estimated to be a nearly $\$ 27$ billion industry. ${ }^{1}$ This sector's growth has been sustained by the expansion of e-learning tools, such as educational mobile applications (EMAs), virtual classrooms, simulation tools, and management system applications. These tools continue to gain popularity among computer and mobile phone users, offering ease of access to information, animated contents, simplistic usability, and interactive platforms. ${ }^{1}$ In the academic sector, e-learning tools using the flashcard approach appear to be effective for improving learner recall of didactic information. A recent study with medical students revealed a 91\% recall accuracy during quizzes when students used flashcards to prepare for quizzes versus a $47 \%$ recall accuracy when other study method were used. ${ }^{2}$ Quizlet is an example of flashcard-based EMA, which offers more than two hundred fourteen million study sets on topics ranging from beginning algebra, to history, to college level econometrics. ${ }^{3}$

EMA, or mobile learning, is defined as learning facilitated by mobile devices or the action of "combining individual learning with anytime and anywhere learning". "The fact that EMAs are highly popular among college students could be explained by a recent study from Baylor University, which revealed that nearly $60 \%$ of college students acknowledged being addicted to their cellphone, and some indicated feeling agitated when it is not in sight. ${ }^{5}$ Students spend between eight and ten hours a day texting, sending emails, checking Facebook, surfing the Internet, and listening to music. ${ }^{5}$ Cellphones and other mobile devices are quickly replacing the lap-top or desk-top computer as the preferred method of accessing the Internet. ${ }^{5}$ Given their potential, flashcard-based EMAs will be the focus of this commentary.

Corresponding author: Serge A. Afeli, PhD, CGBP

Presbyterian College School of Pharmacy

Clinton, SC 29325

Email: safeli@presby.edu
The Use of EMAs in Pharmacy Education

The Accreditation Council for Pharmacy Education (ACPE) requires that all pharmacy programs train their students to become medication experts upon graduation. The required expertise must be achieved by teaching students the knowledge, skills, abilities, behaviors, and attitudes necessary to provide patient-centered care. ${ }^{6}$ The preferred approach for skill development at most pharmacy schools in the United States (U.S.) include didactic courses, and introductory and advanced pharmacy practice experiences. ${ }^{6}$ Thus, pharmacy students are often required to process and memorize a high volume of complex information in a relatively short period of time, which can be challenging. The majority of courses taught in these institutions use the traditional approach, also known as direct instruction, which consists of explicit teaching through lectures or lecture led-demonstration. ${ }^{7}$ Unfortunately, it is becoming more evident that the traditional teaching approach no longer serves students effectively, as it fails to capture their attention and engagement for a full lecture period. ${ }^{8}$ Evidence suggests that students' engagement and learning of a particular topic may be significantly improved when class activities are presented in a game format. ${ }^{9}$ Researchers at the University of Colorado Denver Business School reported that students who played learning games ended up with $11 \%$ higher factual knowledge, $14 \%$ higher skillbased knowledge, and 9\% higher retention rate than those who used other approaches. Players also developed $20 \%$ higher self-efficacy rates than students not exposed to gamestyle learning. ${ }^{10}$ Therefore, EMAs may be a solution to increasing students' engagement and academic success at pharmacy schools in the U.S.

In the past few years several flashcard-based EMAs focusing on pharmacy education have been developed and are available online free-of-charge or for purchase. An evaluation of pharmacy education flashcard-based EMAs was conducted on both android and iOS platforms and below are presented the similarities and differences among five mobile applications, which from the author's stand point, show some interesting features worth discussing. The flashcard-based 
EMAs described in this commentary all utilize, in one way or another, the single answer multiple choice questions (SAMCQ) format to assess student performance, except one.

Quizlet (Quizlet Inc., San Francisco, CA). Quizlet is a free flashcard-based EMA, which offers in-app purchase options for users interested in uploading their own images, obtaining faster help from the support team, or using the application without being interrupted by advertisement. Quizlet has created a community of users in which every member can utilize flashcards developed by other users of the community or simply create his or her own. One unique feature that Quizlet offers is the possibility for teachers to create flashcards for their students using the Quizlet platform. Students can then log into Quizlet and review the course material, in order to prepare for exams. Flashcards covering a wide range of pharmacy education topics, such as pharmacology, therapeutics, and pharmaceutics, are currently available on the Quizlet platform and can help students memorize definitions, concepts, mechanisms of action, brand names or generic names. ${ }^{3}$

NAPLEX Flashcards (BN Inc., Westminster, CA). NAPLEX Flashcards is a free flashcard-based EMA, which offers an inapp purchase option for those interested in text-to-speech technology, working offline, or customizing the text color and background images of their flashcards. Unlike Quizlet, which is primarily for general studies, NAPLEX flashcards' primary focus is to help students successfully pass the North American Pharmacist Licensure Examination (NAPLEX) exam. As such, more than 2900 flashcards have been premade to cover all aspects of the exam ranging from management of care to physiological adaptation and basic care and comfort. This EMA tracks users study progress using the Leitner system and provides detailed statistics on their progression. The Leitner system is a simple implementation of spaced repetition, where cards are re-reviewed at increasing time intervals. ${ }^{11}$ Users may also set a schedule to review a certain number of flashcards in a given time lapse. ${ }^{12}$

FlashRX - Top 250 Drugs (ClinCalc LLC, Arlington Heights, IL). This is a paid flashcard- based EMA specially designed for healthcare students and professionals interested in learning the top 250 medications used in the outpatient setting. The list of drugs used in this application originates from the most commonly prescribed outpatient medications based on net sales, total prescriptions, and unique or emerging therapeutic classes. ${ }^{11}$ Similar to NAPLEX Flashcard, FlashRX also use the Leitner system to track users' progress. Furthermore, FlashRX has some unique features, including a fully customizable card option, the use of a selection algorithm that randomly identifies distractors, and an audio pronunciation option for brand and generic drug names. This application is well suited for students interested in learning brand name, generic name, drug class, indication, adverse effects and typical dosing. ${ }^{11}$
Top 300 Drugs Brand (Brainscape, New York, NY). Unlike FlashRX, Brainscape is a free flashcard-based EMA that allows users to create, share, find and study premade flashcards. It also includes an in-app purchase option for: users interested in learning foreign languages, card reversibility, and flashcards free of advertisement. Similar to Quizlet, Brainscape offers flashcards that go beyond the field of pharmacy education, including law, geography, and psychology. Like FlashRX, the Brainscape Top 300 Drugs Brand are reflective of the top selling medications in America. ${ }^{11}$ It uses an adaptive learning algorithm called Confidence-Based Repetition to help students learn faster and remember longer. ${ }^{13}$ This flashcards' algorithm repeats concepts in a pattern that is optimized to the user's pace. Here, cognitive science research findings regarding the patterns of repetition, color, font style, social interactions, breaks, sounds, humor, animations, achievements, and rewards are used to maximize users' brain speed of learning. ${ }^{14}$

Pharmacynary (SRG Learning LLC, Clinton, SC). Pharmacynary is a free flashcard-based EMA that focuses on the top 300 most prescribed brand name drugs in the U.S. Unlike the four aforementioned flashcard-based EMAs, which use single answer multiple choice questions (SAMCQ), Pharmacynary is the only EMA that uses a modified version of the fill-in-theblank approach. Users are asked to find the correct answer to each question by utilizing a series of randomly disposed letters. In order to receive full credit, users have to first know the correct answer and second be able to spell the answer correctly. ${ }^{15}$ This approach offers the advantage of eliminating the possibility of guessing an answer, thus assessing the user's true knowledge. ${ }^{16}$ In one study, when two groups of final year dental students with similar levels of knowledge were assessed, the group that completed fill-in-the-blank questions performed worse than their counterpart who answered the same questions in a SAMCQ format. ${ }^{16}$ Furthermore, when the group that completed fill-in-the blank questions where given the same questions in a SAMCQ, their score improved. ${ }^{16}$

\section{Conclusions}

The primary mission for pharmacy education is to train students to become medication experts upon graduation by providing the tools to learn, retain, and apply the knowledge presented to them throughout the pharmacy curriculum. The traditional method of teaching, although widely used, has shown some limitations. EMAs could help improve students' recall of didactic information. However, not all EMAs are the same in terms of cost, coverage and functioning. EMAs that are set-up by teachers, prepare students for licensure, and/or reduce the guessing factor are all potentially beneficial tools that could help students become medication experts. 
Acknowledgement: Thanks to Dr. Tiffany Threatt for her critical evaluation of the manuscript.

Conflict of interest: The author of this article is the founder of SRG Learning LLC and creator of the Pharmacynary application. Pharmacynary development was funded by SRG Learning LLC.

\section{References}

1. Docebo. Elearning Market Trends and Forecast 20172021. Published 2016. Available:

https://eclass.teicrete.gr/modules/document/file.ph p/TP271/Additional\%20material/docebo-elearningtrends-report-2017.pdf. Accessed January 17, 2018.

2. Taveira-Gomes T, Prado-Costa R, Severo M, Ferreira MA. Characterization of medical students recall of factual knowledge using learning objects and repeated testing in a movel e-learning system. $B M C$ Med Educ. Jan 24

2015;15:4. https://doi.org/10.1186/s12909-0140275-0

3. Quizlet. Drug Names. Available: https://quizlet.com/subject/drug-names/. Accessed January 6, 2018.

4. Gikas JG, M. Mobile computing devices in higher education: Student perspectives on learning with cellphones, smartphones \& social media. Internet High Educ. 2013;19(2):18-26. https://doi.org/10.1016/j.iheduc.2013.06.002

5. Roberts JA, Yaya LH, Manolis C. The invisible addiction: Cell-phone activities and addiction among male and female college students. J Behav Addict. Dec 2014;3(4):254-265. https://doi.org/10.1556/JBA.3.2014.015

6. Accreditation Council for Pharmacy Education. Accreditation Standards and Key Elements for the Professional Program in Pharmacy Leading to the Doctor of Pharmacy Degree. Published February 2015. Available: https://www.acpeaccredit.org/pdf/Standards2016FINAL.pdf. Accessed January 6, 2018.

7. The Glossary of Education Reform. Hidden Curriculum. Last updated July 13, 2015. Available: http://edglossary.org/hidden-curriculum. Accessed January 22, 2018.

8. Oblinger D. Boomers and Gen-Xers Millennials: Understanding the New Students. Published August 2003. Available: https://www.educause.edu/ir/library/pdf/erm0342. pdf. Accessed February 15, 2018.
9. Pettit RK, McCoy L, Kinney M, Schwartz FN. Student perceptions of gamified audience response system interactions in large group lectures and via lecture capture technology. BMC Med Educ. May 22, 2015;15:92. https://doi.org/10.1186/s12909-0150373-7

10. Morariu JB, E. Serious Games: An Innovative Way to Accelerate Deep Skills. Published January 2012.

Available: http://www-

935.ibm.com/services/multimedia/IBM_Serious_Ga mes_Capabilities.pdf?utm_campaign=elearningindus try.com\&utm_source=\%2F5-reasons-you-need-tobe-using-games-for-corporate-

training\&utm_medium=link. Accessed January 6, 2018.

11. ClinCalc. FlashRX - Top 250 Drugs. Updated October 24, 2015. Available:

http://clincalc.com/mobile/flashrx.aspx. Accessed January 6, 2018.

12. BN Inc. NAPLEX Flashcards. Accessed:

https://play.google.com/store/apps/details?id=com. bh.superflashcard.naplex.android. Accessed January 14, 2018.

13. Waterman S. The Effects of Brainscape's ConfidenceBased Repetition on Two Adults' Performance on Knowledge-based Quizzes. SUNY Digital Repository. Published November 11, 2013. Available:

http://hdl.handle.net/1951/63066. Accessed January 22, 2018.

14. Brainscape. Top 300 Drugs Brand/Generic Flashcards. Available: https://www.brainscape.com/packs/top-300-drugsbrand-generic-2573329. Accessed January 6, 2018.

15. SRG Learning LLC. Pharmacynary: An innovative, Fun, and Interactive Approach to Memorizing the Top 150 Drugs Brand Names. Published July 17, 2017. Available: https://srglearning.com/. Accessed January 22, 2018.

16. Medawela RM, Ratnayake D, Abeyasinghe A, Jayasinghe R, Marambe K. Effectiveness of "fill in the blanks" over multiple choice questions in assessing final year dental undergraduates. Educ Med. Available: https://doi.org/10.1016/j.edumed.2017.03.010. April 2017. 